\title{
PENGARUH IRADIASI SINAR GAMMA TERHADAP RESIDU INSEKTISIDA KLORPIRIFOS PADA BUAH ANGGUR (VITIS VINIFERA L.)
}

\author{
Sofnie M. Chairul \\ Pusat Aplikasi Teknologi Isotop dan Radiasi, Batan, Jln. Lebak Bulus Raya no. 49 Cinere Pasar Jumat \\ Jakarta Selatan \\ e-mail : sofnie@batan.go.id
}

Diterima 24 Mei 2011, diterima dalam bentuk perbaikan 4 Oktober 2011, disetujui 11 Oktober 2011

\begin{abstract}
ABSTRAK
PENGARUH IRADIASI SINAR GAMMA TERHADAP RESIDU INSEKTISIDA KLORPIRIFOS PADA BUAH ANGGUR (Vitis vinifera L.). Telah dilakukan penelitian secara simulasi untuk mengetahui kandungan insektisida klorpirifos di dalam buah anggur akibat diiradiasi dengan sinar gamma. Buah anggur direndam dengan insektisida klorpirifos dengan kadar yang besar yaitu 100 ppm; 200 ppm dan 300 ppm selama 3 menit. Perlakuan yang dilakukan adalah diekstraksi langsung setelah perendaman, penyimpanan selama satu minggu setelah direndam lalu diekstrak, iradiasi setelah penyimpanan pada dosis 0,5; 1,0; dan 1,5 kGy lalu diekstraksi. Pada penentuan kandungan, ekstraksi dilakukan dengan pelarut etil asetat dan natrium sulfat, lalu injeksikan pada gas kromatografi. Hasil perhitungan menyatakan bahwa terjadi penurunan residu klorpirifos dari masing-masing perendaman akibat penyimpanan selama tujuh hari sebesar berturut-turut 7,55; 8,42; dan 18,88 \%, sedangkan akibat iradiasi sinar gamma pada dosis 0,5 kGy akan menurunkan kandungannya berturut-turut 13,90; 19,16; dan 52,79\%, dan pada iradiasi dosis 1,0 kGy akan menurunkan kandungan klorpirifos berturut-turut 14,69; 30,58; dan 57,73\%, dan pada 1,5 kGy akan menurunkan kandungannya berturut-turut 34,45; 36,15; dan 49,79\%.
\end{abstract}

Kata kunci: iradiasi sinar gamma, insektisida, klorpirifos, anggur, gas kromatografi

\begin{abstract}
INFLUENCE OF GAMMA RAYS IRRADIATION TO CHLORPHYRIPHOS INSECTICIDES RESIDUES IN GRAPES (Vitis vinifera L.). Simulation methods to determination of chlorpyriphos insecticides residue in grapes cause effect gamma rays, was done. Fruits of grapes soaked with chlorpyriphos insecticide solution high level concentrated (100 ppm; 200 ppm; and $300 \mathrm{ppm}$ ) for 3 (three minutes). The treatment of the sample was direct of extraction after soaks; extract after storage for one week after soak, and extract after soak after storage for one week after irradiation at 0.5 kGy; $1.0 \mathrm{kGy}$; and $1.5 \mathrm{kGy}$ dose. Extraction methods using ethyl acetate solvent, and using sodium sulphate as to dryed water level in grapes, and then extractan was injected to chromatography gas use electron capture detector. The result indicated that occur of descent of chlorpyrifos residues from eachs soaked consequence at storage for one week was amount 7,55; 8,42; and 18,88 \% respectively, while of consequence irradiation of gamma ray at $0,5 \mathrm{kGy}$ doses, will be descent of chlorpyrifos residues in amount 13,90; 19,16; and 52,79\% respectively, and at 1,0 kGy doses irradiation will be descent in amount 34,45; 36,15 and $49,79 \%$, respectively.
\end{abstract}

Key word: Gamma rays, iradiation, insecticide, chlorpyriphos, vitis vinifera l., chromatography gas.

\section{PENDAHULUAN}

Anggur (Vitis vinifera L.) merupakan tanaman berasal dari Armenia, tetapi dapat tumbuh dan berproduksi Idengan baik di daerah subtropis dan tropis. Komoditi anggur merupakan salah satu dari buah-buahan yang banyak disukai dalam bentuk segar maupun olahan. Perkembangan pertanian sudah lama diprioritaskan oleh petani Indonesia terutama di daerah Jawa Timur dan Bali. ${ }^{(1,2)}$

Salah satu kendala dalam usaha peningkatan mutu dan produksi anggur adalah serangan hama dan penyakit pada daun, tunas sulur dan buah. Oleh karena itu agar tanaman jauh dari gangguan hama dan panyakit, maka dilakukan tindakan preventif, yaitu dengan menyemprotkan pestisida pada saat tertentu. Salah satu jenis pestisida yang digunakan pada tanaman anggur adalah jenis organofosfat, diantaranya klorpirifos. ${ }^{(3)}$

Penggunaan pestisida dalam proses produksi pertanian dapat mengakibatkan adanya residu pada hasil panen dan dapat membahayakan kesehatan..$^{(4,5)}$ Untuk menghindari hal ini dan dalam mengkonsumsi buah anggur, maka perlu dilakukan penelitian untuk melihat apakah terjadi penurunan residu atau hilangnya residu 
klorpirifos pada buah anggur hasil panen apabila dilakukan irradiasi dengan sinar gamma. Sinar gamma mempunyai daya tembus yang paling besar bila dibandingkan dengan sinar alfa atau sinar beta, oleh karena itu sinar gamma banyak digunakan di dalam pengolahan makanan, terutama pengawetan makanan, yang biasa disebut dengan iradiasi. ${ }^{(6,7,8)}$. Penggunaan iradiasi sinar gamma pada bahan pangan selain untuk tujuan pengawetan dapat pula digunakan untuk menurunkan residu kimia. Dosis yang aman untuk iradiasi sinar gamma yang digunakan untuk buah-buahan segar pada umumnya adalah sebesar 0,5-1,0 kGy. ${ }^{(9,10,11,12)}$

Untuk mengetahui residu pestisida dalam buah anggur setelah perlakuan, ditetapkan dengan metode Gas Kromatografi. Penelitian dilakukan dengan cara simulasi, dimana anggur direndam dengan pestisida klorpirifos dalam beberapa konsentrasi perlakuan, kemudian dilakukan proses penyimpanan selama 7 hari, lalu dilakukan iradiasi dan dibandingkan dengan sampel tanpa iradiasi ${ }^{(11,13,14) .}$

Perendaman buah anggur di dalam larutan klorpirifos bertujuan agar pada buah anggur terdapat residu yang cukup besar, sehingga terlihat terjadinya penurunan residu setelah diiradiasi, dan jika diiradiasi akan terjadi peruraian klorpirifos menjadi senyawa yang tidak bersifat pestisida. Kemungkinan akan terjadi peruraian klorpirifos akibat oksidasi desulfurisasi sehingga terbentuk oxon, dan jika melalui oksidasi dan hidrolisis, akan dihasilkan trikloropiridol. Walaupun deklorinasi dari klorpirifos tidak teridentifikasi pada tanaman, tetapi deklorinasi 3-dekloroklorpirifos teridentifikasi di dalam serangga. ${ }^{(12)}$<smiles>CCOP(=S)(OCC)Oc1nc(Cl)c(Cl)cc1Cl</smiles>

Klorpirifos

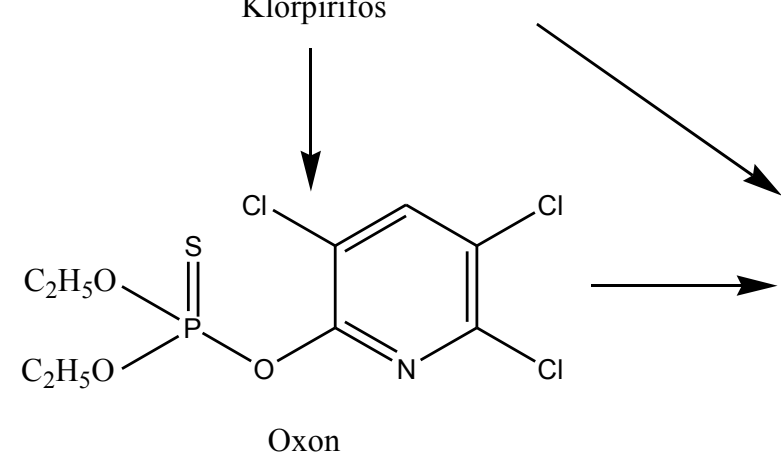<smiles>CCOP(=S)(OCC)Oc1nc(Cl)c(Cl)cc1Cl</smiles><smiles>Oc1nc(Cl)c(Cl)cc1Cl</smiles>

Trikloropiridol

Gambar 1. Skema bentuk peruraian insektisida klorpirifos

\section{METODOLOGI}

Bahan. Bahan yang digunakan dalam penelitian ini adalah buah anggur dari pasar swalayan, baku pembanding klorpirifos dengan kemurnian 99\% (chemical company Midland), Dursban 200 EC dengan bahan aktif klorpirifos, natrium sulfat p.a, etil asetat p.a dan aseton p.a.

Alat. Alat yang digunakan dalam penelitian ini adalah Iradiator IRPRASENA, kromatografi gas model GC-14A Shimadzu yang dilengkapi detektor penangkap elektron (ECD) dan kolom kapiler OV-101 dalam kromosorb WAW, bamix mode M 122, dan alat-alat pendukung lainnya yang ada di laboratorium.

Penyediaan Sampel. Buah anggur merah diambil secara acak dari salah satu pasar swalayan, dengan cara menempatkannya pada keranjang, kemudian diambil dari sisi-sisi yang berlawanan. Dari sini, diacak kembali dengan meletakkan di dalam wadah, lalu dibagi empat. Kemudian kembali diambil dua sisi yang berlawanan. Sampling di ulang beberapa kali, sehingga terkumpul sebanyak $150 \mathrm{~g}$ untuk tiga kali pengulangan.

Proses Perendaman Buah Anggur. Dibuat tiga macam larutan perendam dengan bahan aktif klorpirifos pada konsentrasi 100 ppm; 200 ppm dan 300 ppm. Larutan dibuat dengan cara menimbang Dursban 200 EC (kandungan klorpirifos 20\%) sesuai konsentrasi yang diperlukan dan dilarutkan dalam 3 (tiga) liter air. Larutan diaduk sampai merata dan homogen. Buah anggur direndam ke dalam masing-masing larutan klorpirifos selama 3 menit, lalu diangkat dan ditiriskan. Buah anggur dibagi menjadi 5 (lima) perlakuan : 

a. langsung dianalisis
b. penyimpanan 7 hari
c. penyimpanan 7 hari dan diiradiasi pada dosis $0,5 \mathrm{kGy}$;
d. penyimpanan 7 hari dan diradiasi pada dosis $1,0 \mathrm{kGy}$
e. penyimpanan 7 hari dan diradiasi pada dosis $1,5 \mathrm{kGy}$

Ekstraksi Buah Anggur. Sebanyak 50 gram buah anggur yang sudah dipotong-potong kecil ditimbang dengan seksama. Ditambahkan \pm 50 gram natrium sulfat anhidrid, diaduk sampai merata. Kemudian diekstrak dengan $100 \mathrm{ml}$ pelarut etil asetat selama 3 (tiga) menit menggunakan Bamix. Campuran didiamkan sampai terpisah antara endapan dan supernatant. Injeksikan supernatant pada alat gas Kromatografi sebanyak 3 (tiga) $\mu$ l dengan kondisi alat kolom berisi OV-101 dalam kromosorb WAW, detektor penangkap elektron, suhu kolom $230{ }^{\circ} \mathrm{C}$, suhu injektor $250{ }^{\circ} \mathrm{C}$, suhu detektor $250{ }^{\circ} \mathrm{C}$. Residu klorpirifos dalam buah anggur dituangkan pada kromatogram berupa puncak sampel yang dibandingkan dengan standar pembanding klorpirifos, dengan perhitungan sebagai berikut:

$$
\mathrm{R}=\frac{\frac{\mathrm{T}_{\text {spl }}}{\mathrm{T}_{\text {std }}} \times \frac{\mathrm{C}_{\text {std }} \times \mathrm{V}_{\text {std }}}{\mathrm{V}_{\text {spl }}}}{\mathrm{W}_{\text {spl }}} \times \mathrm{V}_{\mathrm{a}}
$$

dimana:

$\mathrm{R}=$ residu klorpirifos $(\mathrm{ppb}), \mathrm{Tspl}=$ tinggi puncak sampel $(\mathrm{mm}), \mathrm{Tstd}=$ tinggi puncak standar pembanding klorpirifos $(\mathrm{mm}), C$ std $=$ konsentrasi standar pembanding $(\mathrm{ng} / \mu \mathrm{l})$, Vstd = volume standar pembanding yang diinjeksikan $(\mu \mathrm{l}), \mathrm{Vspl}=$ volume sampel yang diinjeksikan $(\mu \mathrm{l}), \mathrm{Va}=$ volume akhir sampel $(\mu \mathrm{l})$, Wspl $=$ berat sampel yang ditimbang (gram).

\section{HASIL DAN PEMBAHASAN}

Kandungan residu klorpirifos terhadap buah anggur yang telah direndam dengan larutan klorpirifos pada konsentrasi 100 ppm, untuk perlakuan langsung ekstraksi setelah direndam selama 3 menit, didapatkan rata-rata 4,66 ppm. Pada perlakuan penyimpanan selama 7 hari, konsentrasi menurun menjadi 3, 78 ppm. Buah anggur yang disimpan, kemudian diiradiasi pada dosis $0,5 \mathrm{kGy}$; 1,0 kGy dan 1,5 kGy. Kandungan residu adalah berturutturut 2,20 ppm; 1,97 ppm dan 2,34 ppm seperti yang disajikan pada Gambar 2.Jika dilihat persen penurunannya dan setelah dibandingkan antara diekstrak langsung setelah perendaman dengan penyimpanan, dan setelah diiradiasi dengan dosis 0,$5 ; 1,0$ dan 1,5 kGy maka hasilnya dapat lihat pada Gambar 5, yaitu sebesar berturutturut $18,88 \% ; 52,74 ; 57,73$ dan $49,79 \%$. Sehingga semakin tinggi dosis iradiasi, maka semakin turun atau berkurang residu insektisida dalam buah anggur.

Kandungan residu klorpirifos terhadap buah anggur yang telah direndam dengan larutan klorpirifos pada konsentrasi 200 ppm, untuk buah anggur yang langsung ekstraksi setelah direndam selama 3 menit didapatkan konsentrasi rata-rata 10,07 ppm. Pada gambar 3 terlihat bahwa untuk perlakuan penyimpanan selama 7 hari setelah perendaman adalah 9,31 ppm; setelah diiradiasi pada 0,5 kGy; 1,0 kGy dan 1,5 kGy setelah penyimpanan 7 hari, berturut-turut adalah $8,67 \mathrm{ppm} ; 8,59 \mathrm{ppm}$ dan $6,43 \mathrm{ppm}$. Jika dilihat persen penurunannya bila dibandingkan antara diekstrak langsung setelah perendaman dengan penyimpanan, iradiasi 0,$5 ; 1,0$ dan 1,5 kGy maka terlihat pada Gambar 5, yaitu sebesar berturut-turut 7,55 \%; 13,90 \%; 14,69 \% dan 36,15\%. Sehingga semakin tinggi dosis iradiasi, maka penurunan residu semakin besar.

Kandungan residu klorpirifos terhadap buah anggur yang telah direndam dengan larutan klorpirifos pada konsentrasi 300 ppm, untuk buah anggur yang langsung ekstraksi setelah direndam selama 3 menit didapatkan konsentrasi rata-rata 11,64 ppm. Pada Gambar 4 terlihat bahwa untuk perlakuan penyimpanan selama 7 hari setelah perendaman adalah 10,66 ppm; setelah diiradiasi pada 0,5 kGy; 1,0 kGy dan 1,5 kGy setelah penyimpanan 7 hari, berturut-turut adalah $9,41 \mathrm{ppm} ; 8,08 \mathrm{ppm}$ dan $7,63 \mathrm{ppm}$. Jika dilihat persen penurunannya bila dibandingkan antara diekstrak langsung setelah perendaman dengan penyimpanan, iradiasi 0,$5 ; 1,0$ dan 1,5 kGy maka terlihat pada Gambar 5, yaitu sebesar berturut-turut 8,08 \%; $19,16 \% ; 30,58 \%$ dan 34,45 \%. Sehingga semakin tinggi dosis iradiasi, maka penurunan residu semakin tinggi. 
Penurunan kandungan klorpirifos akibat penyimpanan dan iradiasi sinar gamma dapat disebabkan karena insektisida klorpirifos termasuk pestisida bersifat semi persisten yang mempunyai waktu paro 60-120 hari, sehingga akibat penyimpanan selama 7 hari, maka klorpirifos sedikit terurai. ${ }^{(4)}$

Selain itu klorpirifos juga termasuk pestisida yang bersifat non sistemik, sehingga klorpirifos hanya terdapat pada pemukaan buah anggur. Dengan iradiasi sinar gamma, kadar residu klorpirifos menurun, penurunan ini dapat disebabkan proses iradiasi gamma yang dapat menyebabkan kerusakan pada struktur kimia sehingga terurai menjadi senyawa lain. ${ }^{(2)}$

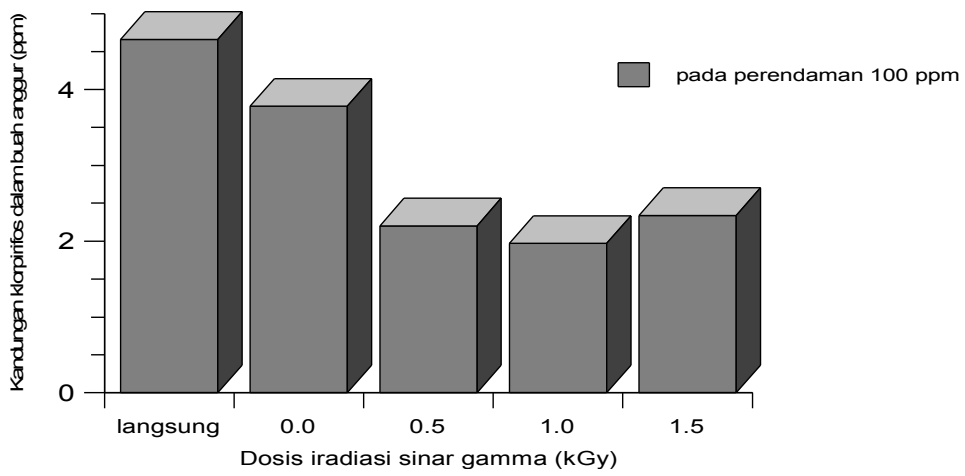

Gambar 2. Residu Insektisida klorpirifos dalam buah anggur pada perendaman dengan klorpirifos konsentrasi 100 ppm setelah diiradiasi dengan sinar gamma dibandingkan tanpa iradiasi, dan penyimpanan

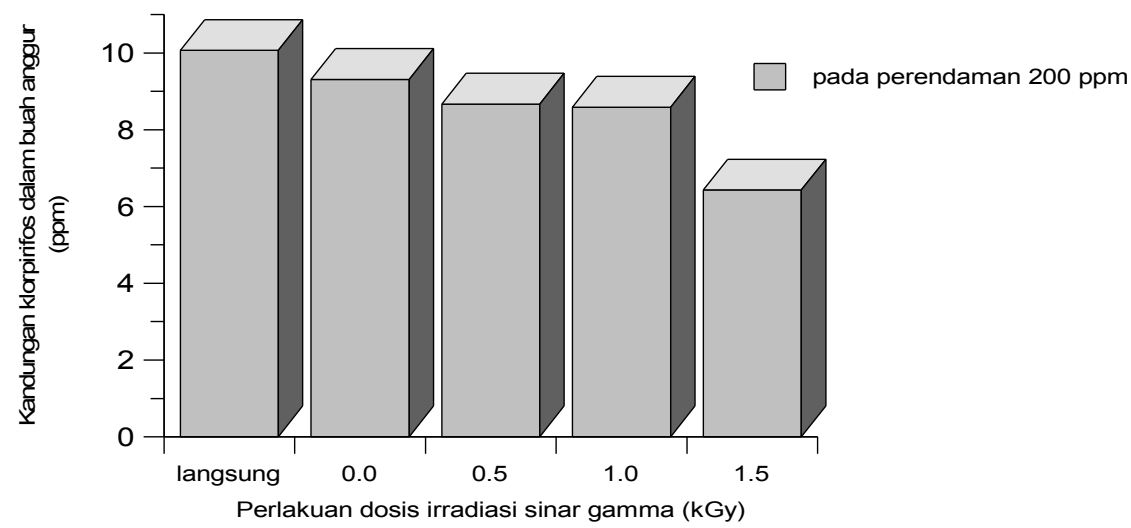

Gambar 3. Residu Insektisida klorpirifos dalam buah anggur pada perendaman dengan klorpirifos konsentrasi 200 ppm setelah diiradiasi dengan sinar gamma dibandingkan tanpa iradiasi, penyimpanan

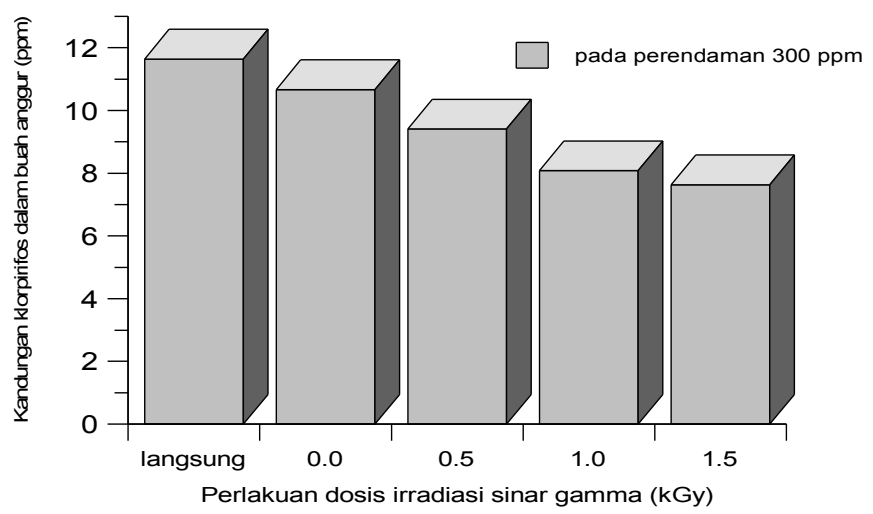

Gambar 4. Residu Insektisida klorpirifos dalam buah anggur pada perendaman dengan klorpirifos konsentrasi 300 ppm setelah diiradiasi dengan sinar gamma dibandingkan tanpa iradiasi, penyimpanan 


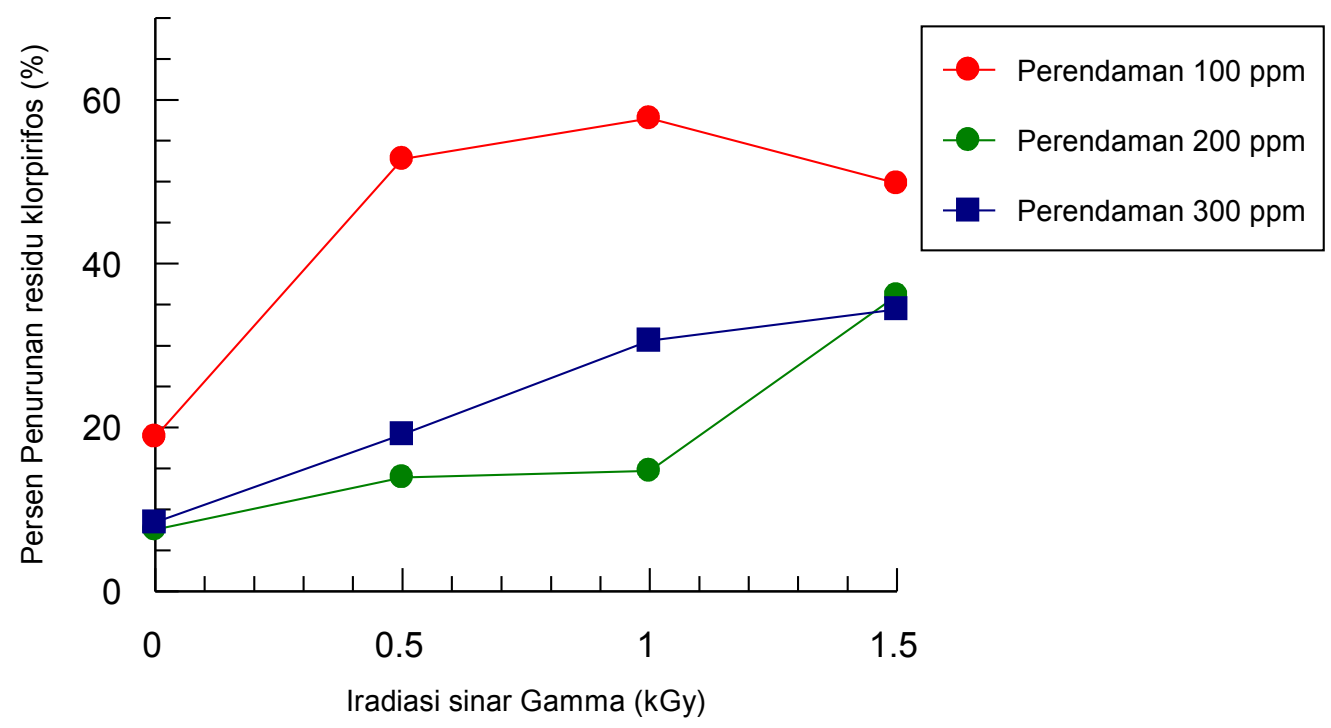

Gambar 5. Persen penurunan kandungan klorpirifos pada perendaman 100 ppm; 200 ppm dan 300 ppm akibat diiradiasi dengan sinar gamma, bila dibandingkan dengan kandungan yang diekstraksi langsung tanpa penyimpanan

\section{KESIMPULAN}

1. Kandungan residu insektisida klorpirifos pada buah anggur yang langsung diekstraksi setelah melalui proses perendaman dengan klorpirifos konsentrasi 100; 200; dan 300 ppm berturut- turut adalah 4,66; 10, 07; dan $11,64 \mathrm{ppm}$.

2. Perlakuan penyimpanan selama 7 hari dari setiap konsentrasi perendaman, dapat menurunkan kandungan residu klorpirifos baik setelah direndam dengan larutan klorpirifos 100; 200; dan 300 ppm, berturut-turut adalah 3,$78 ; 9,31$; dan 10,66 ppm.

3. Perlakuan penyimpanan 7 hari dan lalu diiradiasi dengan sinar gamma pada dosis $0,5 \mathrm{kGy}$ pada setiap perendaman berturut-turut adalah 52,79; 13,90; dan 19,16\%. Pada iradiasi 1,0 kGy pada setiap konsentrasi perendaman berturut-turut sebesar 57,$73 ; 14,69$; dan 30,58 \%. Dan pada iradiasi $1,5 \mathrm{kGy}$ pada setiap konsentrasi perendaman menurunkan kadar residu klorpirifos sebesar berturut-turut 49,79; 36,15; dan 34,45 $\%$.

\section{DAFTAR PUSTAKA}

1. DEPARTEMEN PERTANIAN, Penanganan Pasca Panen Buah Anggur, Direktorat Jenderal Pertanian Tanaman Pangan, Jakarta (1991)

2. DEPARTEMEN PERTANIAN, Budidaya Anggur, Pusat Penelitian dan Pengembangan Hortikultura, Jakarta (1991)

3. SETIADI, Majalah Bertanam Anggur, Penebar Swadaya, 1-2, (2003), 101-105.

4. DJOJOSUMARTO, Pestisida dan Aplikasinya, Agromedia Pustaka, 89-90, (2008), 204-257.

5. DEPARTEMEN PERTANIAN, Metode Pengujian Residu Pestisida dalam Hasil Pertanian, Jakarta (1997)

6. T.R. MUCHTADI, Petunjuk Laboratorium Technologi Proses Pengolahan Pangan, Bogor, IPB, (1988) 181-184

7. F.G. WINARNO, Pengantar Teknologi Pangan, PT. Gramedia, 27 (1980), 54-57.

8. IRAWATI, Z., Pengembangan Teknik Nuklir untuk Meningkatkan keamanan dan Daya Simpan Bahan Pangan, J. Aplikasi Isotop dan Radiasi, 3 (2),41 (2007)

9. S. WIRYOSIMIN. Mengenal Azas Proteksi Radiasi, Bandung, Penerbit ITB, (1995) 11-60 
10. R.P. TANHINDARTO, dan Z. IRAWATI, "Status Litbang Pengawetan Makanan Menggunakan Radiasi Pengion", Prosiding Seminar Nasional Kimia dalam Industri dan Lingkungan, Jaringan Kerjasama Kimia Indonesia, Yokyakarta, (2005) 137-139.

11. S.M. CHAIRUL, "Penurunan Residu Insektisida Klorpirifos pada Wortel Akibat Iradiasi Sinar Gamma", Risalah Pertemuan IImiah Penelitian dan Pengembangan Aplikasi Isotop dan Radiasi, Badan Tenaga Nuklir Nasional, Jakarta (2003). 151-153.

12. HIROYASU AIZAWA, Metabolic Maps of Pesticides, Yokohama Japan (1982)

13. SOFNIE M. CHAIRUL, Pengaruh Pencucian dan Pemasakan terhadap Residu Insektisida Klorpirifos pada Wortel (Daucus carota L.), J. IImiah Pertanian Gakuryoku, 12 (1) (2006) 26-30

14. SOFNIE M. CHAIRUL dan ACHMAD NASROH KUSWADI, "Penurunan Kandungan Residu Insektisida Dimetoat dalam Cabai Merah Capsicum annum L akibat Iradiasi Sinar Gamma," Prosiding Seminar Nasional SDM Teknologi Nuklir, Yokyakarta (2006) 21-22 